\title{
Correspondence Analysis in International Sci-Tech Cooperation Patterns and University Resources
}

\author{
$\mathrm{Li} \mathrm{Li}^{1}$, Zhengning Feng ${ }^{1}$, Xuezhu Gao ${ }^{1}$
}

${ }^{1}$ Shenzhen Graduate School, Harbin Institute of Technology, Shenzhen, China.

Email: ximlli@yahoo.com.cn, fengzhengning@yahoo.com.cn, xuezhugaobest@163.com

Received November $15^{\text {th }}, 2010$; revised January $20^{\text {th }}, 2011$; accepted February $27^{\text {th }}, 2011$.

\begin{abstract}
This paper studies the relationship between cooperation patterns and resources of university in international science and technology cooperation and exchanges based on correspondence analysis method, makes assessment and judgment about pattern selection of international science and technology cooperation between universities in terms of human resources, technology level, financial resources, analyzes the gains or losses of international science and technology cooperation in primary patterns and advanced patterns, explores the existing problems and trends of international science and technology cooperation between universities, and put forward corresponding countermeasures and suggestions.
\end{abstract}

Keywords: International Science and Technology Cooperation, Correspondence Analysis Method, Cooperation Pattern

\section{Introduction}

With global trends of the cooperation of economic and technological, international science and technology cooperation and effective usage of global scientific and technological resources are the important ways to promote national or regional scientific and technological development, to enhance the national or regional industrial competitiveness, and to promote economic growth. Universities, as the main participant in international science and technology cooperation, and the main provider of human resources and technological resources for international science and technology cooperation, occupy an irreplaceable important role; international science and technology cooperation between universities is a key factor in the new round of global scientific resources restructuring and technological cross-border transferring. Analyzing China's universities resource conditions of international science and technology cooperation, cooperation models, status and trends and strengthening international science and technology cooperation and exchanges among universities are of great significance to cultivate creative talents, to enhance scientific and technological innovation capability and to build an open system of independent innovation system.

\section{Literature Review and Research Questions}

In recent years, scholars in this area launched a series of related studies, Finholt and Olson (1997) proposed an organizational pattern for scientific cooperation established by a virtual network organization model [1]. Basu and Aggarwal (2001) studied the influence of international science and technology cooperation on an academic institution (university), and the publishing of international joint papers achievement is beneficial for an academic institution to improve its own performance [2]. Smeby and Trondal (2005) researched some of the linkages between the trends of universities in international science and technology cooperation and some factors, such as globalization, policy conditions and geography, on the basic of statistics and questionnaire survey about five kinds of patterns of international cooperation and exchanges in three periods of three universities of Norway [3]. Beaver (2001) reviewed some previous and current studies on scientific cooperation, proposed new direction for future research, and studied the motives and characteristics of cooperation [4]. Papon (2004) studied the role that basic scientific and technical cooperation organizations play in Europe scientific and technical cooperation [5]. Fuqua et al. (2004) studied the interdisciplinary scientific cooperation [6]. Yamashita and Okubo (2006) carried out case studies and analyzed the status of international science and technology cooperation [7]. Roderik Ponds (2009) conducted a research on the limits to internationalization of scientific research collaboration [8]. Li et al. (2001) proposed the necessity for universi- 
ties to carry out international science and technology cooperation [9]. Feng et al. (2002) studied the law application mechanism for carrying out international science and technology cooperation in universities [10]. Zhang (2003) studied the international science and technology cooperation of Research University, also used the cooperation pattern adopted by Zhejiang University International science and technology cooperation as example, expounded the conditions, characteristics for establishing cooperation pattern and role it plays in promoting school development [11]. Li et al. (2005) studied the science and technology cooperation between or among the east-west universities and discussed the cooperation patterns and development ideas [12]. Hu (2006) studied Tsinghua University's international science and technology cooperation, summed up experiences and put forward some policies and suggestions [13]. Wu (2007) studied the universities international science and technology cooperation in a global context [14]. Zhang (2009) studied China's university international science and technology cooperation patterns and characteristics [15]. This paper studies the universities international science and technology cooperation from two dimensions, the resource conditions and cooperation pattern of universities international science and technology cooperation, reveals the relationship and general law of resource conditions and cooperation pattern in carrying out international science and technology cooperation in universities and provides references for promoting the further development of cooperation and exchange of international science and technology in China's universities.

\section{Research Method}

Correspondence analysis method is a multiple dependent variables statistical analysis techniques, which reveals the connections among variables through interactive summary table consisting of qualitative variables. This method can not only describe the links between variables through the distribution maps of variable type, but also reveal the differences in of one variable and correspondence relationship in various categories of different type of variable.

We assume for the question studied that: resource conditions (human resources, science and technology level, financial resources) of a college of science and technology cooperation, to a large extent, determine the level at which it carries out international science and technology cooperation and the stage, which can be reflected in the different cooperation models chosen by universities. That is, there exists a kind of corresponding relationship, mutual influence and constraints, between the resource conditions and cooperation model of universities international science and technology cooperation.
For the research of the relationship, the main content is to study that: what kind of cooperation pattern a university with a certain level of resource condition will tend to choose? Since the data we obtained are largely qualitative variable data, a quantitative analysis of the variable data is inevitable. Generally, analyzing qualitative variables needs to take non-linear statistical methods, but the research variable, "model" needs to be divided into many categories, while the non-linear statistical methods can not be visually revealed the contact between the variables, so this paper conducted research by adopting correspondence analysis method.

\section{Variable Establishment and Data Description}

The variables established in this paper are to describe the two dimensions, which are the resource and cooperation patterns of university international science and technology cooperation.

\subsection{Establishment of International Sci-Tech Cooperation Resource Variable}

Information, technology, talent and capital are the four essential elements for international scientific and technological cooperation. These four elements flow between cooperative participants every time international scientific and technological cooperation happens, and the flowing direction is up to the degree in which the participants own them. That is, just because of these four elements are differently owned by cooperative participants, the cooperation make sense. As the element, information, is difficult to be a be described by a quantitative data, so here we just use the these three variables, technology, human resources and financial resources to describe the resource conditions of international science and technology cooperation in various universities.

\subsection{Establishment of International Sci-Tech Cooperation Pattern Variable}

As respect to the universities international science and technology cooperation pattern, we can get different types of results, as classification method and point of view changes. According to Professor Zhang Ju of science and technology department of Zhejiang university, universities international science and technology cooperation is divided into: the inter-governmental cooperation; the nongovernmental organizations; the cooperation projects obtained through the way of application-oriented cooperation and free application and sponsored by the international foundations or non-governmental organizations; the joint laboratory, research and development center established by the cooperating parties [11]. While some scholars according to different cooperation parties 
build universities international scientific and technological cooperation into: inter-school science and technology cooperation, science and technology cooperation between universities and enterprises, science and technology cooperation involving includes government and universities. Here we classified and summarized the universities international science and technology cooperation only in terms of international science and technology cooperation content and form, for those cooperation models that rarely appeared is out of our consideration. Through a large number of data collection and careful study and choice, ultimately, this paper totally got 11 kinds of international science and technology cooperation patterns commonly used in universities: international academic conferences, cooperative research, joint development, joint institution, joint training, scholar visits and exchanges, information exchange, visit and investigation, joint laboratory, sharing of network resources and government cooperation programs.

The following Table 1 describes the definitions and characteristics of these 11 types of universities of international science and technology cooperation pattern; in this paper we use $\mathrm{M}$ represent the pattern, and $\mathrm{H}, \mathrm{S}, \mathrm{C}$ represent human resource, technological level and financial resources respectively.

\subsection{The Collection of Variable Data}

Data are from the China's 15 universities with strong comprehensive strength, the choice of these samples takes the validity, the unbiasedness and the sufficiency of the data obtained into consideration. First of all, these 15 universities have strong research and technological ability, a better scientific talent pool and hardware foundation, and the launching of a broad and active international science and technology cooperation and exchanges; Secondly, in order to avoid deviation in research results caused by the different types of school, the 15 universities we selected are all belong to the comprehensive colleges or the polytechnic colleges. In addition, the choice of 15 universities give full consideration to the geographical distribution factor, in geography, the distribution of these samples are over the country, from the most southern to the most northern, from the east coast to the west inland. Finally, in order to achieve the objective of the study, there is also an obvious gap layer, in terms of scientific and technological resource conditions, between these samples. According to the national comprehensive

Table 1. International science and technology cooperation patterns between universities.

\begin{tabular}{|c|c|c|}
\hline & Cooperation patterns & Characteristics \\
\hline 1 & $\begin{array}{l}\text { International academic } \\
\text { conference }\end{array}$ & $\begin{array}{l}\text { A kind of conference exchange widely used in international science and technology exchange, in order to } \\
\text { expand achievements influence, facilitate spread of new ideas and establish international cooperation. }\end{array}$ \\
\hline 2 & Cooperative research & $\begin{array}{l}\text { For the same research project, cooperative parties conduct the research in cooperation or division under the } \\
\text { unified planning and organization. }\end{array}$ \\
\hline 3 & Joint development & $\begin{array}{l}\text { On the basis of certain scientific research achievement, cooperative parties co-develop the product with a } \\
\text { market target or the project with an engineering objective. }\end{array}$ \\
\hline 4 & Joint institution & $\begin{array}{l}\text { Cooperative parties put the human resources, capital and equipment together, and open exchange center and } \\
\text { research centre jointly, for the aim of researching cooperatively. }\end{array}$ \\
\hline 5 & $\begin{array}{l}\text { Scholars visits and } \\
\text { exchanges }\end{array}$ & $\begin{array}{l}\text { Experts invited from abroad or send overseas will give a series of academic exchange activities, such as } \\
\text { lectures, seminar and consultation. }\end{array}$ \\
\hline 6 & Joint training & $\begin{array}{l}\text { Jointly open school or training and provide to students the opportunity to study in another school by in- } \\
\text { ter-school exchange. }\end{array}$ \\
\hline 7 & Information exchange & $\begin{array}{l}\text { Through the methods of character, sound and image, computer network and entity to exchange technology } \\
\text { and experience, communicate scientific thoughts and spread scientific technologies. }\end{array}$ \\
\hline 8 & Visit and investigation & $\begin{array}{l}\text { The objective-oriented investigations conducted by scientific and technological personnel, in order to under- } \\
\text { stand the sci-tech profile, the academic level of some field or an advanced technology }\end{array}$ \\
\hline 9 & Joint laboratory & $\begin{array}{l}\text { Laboratories established by joint investment of cooperative parties, government, universities or other institu- } \\
\text { tions, which are managed jointly and where co-research is conducted. }\end{array}$ \\
\hline 10 & $\begin{array}{l}\text { Sharing of network } \\
\text { resources }\end{array}$ & $\begin{array}{l}\text { Spontaneously or driven by the Government, to establish cooperation alliance and network of cooperation } \\
\text { inter-school or between school and multinational corporation, in order to carry out exchanges and coopera- } \\
\text { tion. }\end{array}$ \\
\hline 11 & $\begin{array}{l}\text { Government cooperation } \\
\text { programs }\end{array}$ & $\begin{array}{l}\text { Through the relevant inter-governmental sci-tech cooperation agreements, plans, projects, with a certain } \\
\text { funding, organize and regulate the conduction of foreign science and technology cooperation. }\end{array}$ \\
\hline
\end{tabular}


strength rank of universities in 2008, the 15 universities rank as follows, from high to low, in respect to comprehensive strength, that is: Tsinghua University, Zhejiang University, Fudan University, Huazhong Science and technology, Harbin Institute of Technology, Chongqing University, Beijing Polytechnic University, Northeastern University, Shanghai University, Jinan University, Southwest Jiaotong University, Jiangsu University, Yunnan University, Chengdu University of Technology, Heilongjiang University.

The data of the variable, international science and technology cooperation pattern (M) comes from the tendency of science and technology cooperation model selection, when the various universities carry out international technological cooperation activities. The acquisition of this data is a qualitative conclusion gained through the analysis and judgment of the Statistical Yearbooks, which contain all the Statistical Yearbooks since the beginning of the science and technology cooperation in various universities. The conclusion shows that some universities tend to choose certain science and technology cooperation model (Table 2 with $\sqrt{ }$ ). To this qualitative judgment, we follow the following three points: firstly, there is focused description of a particular cooperation pattern in an university's statistical information over the resent years; secondly, for a university there should be a standard about the number of launching a particular cooperation pattern every year. thirdly, there is an increasing trend in carrying a particular cooperation model for a college over the recent years. Based on the above method, after sufficiently information inquiry and researching, we made the qualitative judgment.

Variable, human resources $(\mathrm{H})$, data is defined by the available number of graduate and doctoral students in various universities, we use the number of postgraduate and doctoral students in Tsinghua University (ranked first over comprehensive strength) as a benchmark (set to unit 1); for other universities, using the number of people to divide the number of Tsinghua University, then they will receive the final data. Variable, technology level (S), data is defined by the number of patents obtained in 2007 by various universities. And the number of patents in Tsinghua University is used as a benchmark (set to unit 1). The number of patents in other universities divides that of Tinghua's, the result coming out is the final data for each other universities. Variable, financial resources $(\mathrm{C})$, data is presented by the research funds of various universities in 2007. We also adopt research funds of Tsinghua University as a benchmark (set to unit 1), other university's research funding divides that of Tsinghua University's, then research funding, data obtained as a the final data. On this basis, the human resources $(\mathrm{H})$, technology levels (S), financial resources (C) were divided into three levels representing different levels of science and technology cooperation resource conditions. The human resource is divided into $0-0.4,0.4-0.7$, above 0.7 , three levels; technology level is divided into $0-0.1,0.1-0.4$, above 0.4 , three levels; also the financial resources into

Table 2. Relationship on resources and patterns in university international sci-tech cooperation.

\begin{tabular}{|c|c|c|c|c|c|c|c|c|c|c|c|c|c|c|}
\hline & \multicolumn{3}{|c|}{ Factors } & \multicolumn{11}{|c|}{ Patterns } \\
\hline & $\begin{array}{c}\text { Human } \\
\text { resource }(\mathrm{H})\end{array}$ & $\begin{array}{l}\text { Technology } \\
\text { level (S) }\end{array}$ & $\begin{array}{c}\text { Capital } \\
\text { resource }(\mathrm{C})\end{array}$ & 1 & 2 & 3 & 4 & 5 & 6 & 7 & 8 & 9 & 10 & 11 \\
\hline Tsinghua University & 1 & 1 & 1 & & $\sqrt{ }$ & $\sqrt{ }$ & $\sqrt{ }$ & & & & & $\sqrt{ }$ & & $\sqrt{ }$ \\
\hline Zhejiang University & 0.93 & 1.3 & 0.53 & & $\sqrt{ }$ & $\sqrt{ }$ & $\sqrt{ }$ & & & & & & $\sqrt{ }$ & $\sqrt{ }$ \\
\hline Fudan University & 0.68 & 0.41 & 0.37 & $\sqrt{ }$ & $\sqrt{ }$ & $\sqrt{ }$ & $\sqrt{ }$ & & $\sqrt{ }$ & & & & $\sqrt{ }$ & \\
\hline $\begin{array}{l}\text { Huazhong University of Science } \\
\text { and technology }\end{array}$ & 1.03 & 0.16 & 0.32 & $\sqrt{ }$ & $\sqrt{ }$ & $\sqrt{ }$ & & $\sqrt{ }$ & & & & $\sqrt{ }$ & & $\sqrt{ }$ \\
\hline Harbin Institute of Technology & 0.94 & 0.43 & 0.40 & $\sqrt{ }$ & $\sqrt{ }$ & $\sqrt{ }$ & & & $\sqrt{ }$ & & & $\sqrt{ }$ & & \\
\hline Chongqing University & 0.91 & 0.17 & 0.21 & $\sqrt{ }$ & $\sqrt{ }$ & & & $\sqrt{ }$ & $\sqrt{ }$ & & & & & \\
\hline Beijing Polytechnic University & 0.41 & 0.06 & 0.23 & $\sqrt{ }$ & & & $\sqrt{ }$ & $\sqrt{ }$ & $\sqrt{ }$ & & $\sqrt{ }$ & & & \\
\hline Northeastern University & 0.53 & 0.10 & 0.11 & $\sqrt{ }$ & & $\sqrt{ }$ & & & & & $\sqrt{ }$ & & & \\
\hline Shanghai University & 0.46 & 0.24 & 0.18 & & & $\sqrt{ }$ & & $\sqrt{ }$ & $\sqrt{ }$ & & $\sqrt{ }$ & & & \\
\hline Jinan University & 0.34 & 0.06 & 0.13 & $\sqrt{ }$ & & & & $\sqrt{ }$ & $\sqrt{ }$ & & & & & \\
\hline Southwest Jiaotong University & 0.45 & 0.08 & 0.11 & & $\sqrt{ }$ & & & $\sqrt{ }$ & $\sqrt{ }$ & & $\sqrt{ }$ & & & \\
\hline Jiangsu University & 0.34 & 0.10 & 0.09 & $\sqrt{ }$ & & & & $\sqrt{ }$ & & & $\sqrt{ }$ & & & \\
\hline Yunnan University & 0.41 & 0.06 & 0.06 & $\sqrt{ }$ & & & & $\sqrt{ }$ & $\sqrt{ }$ & $\sqrt{ }$ & & & & \\
\hline $\begin{array}{l}\text { Chengdu University of } \\
\text { Technology }\end{array}$ & 0.15 & 0.04 & 0.05 & $\sqrt{ }$ & & & & $\sqrt{ }$ & & $\sqrt{ }$ & & & & \\
\hline Heilongjiang University & 0.12 & 0.03 & 0.06 & & & & & $\sqrt{ }$ & & $\sqrt{ }$ & & & & \\
\hline
\end{tabular}

Note: 1 - International academic conference, 2 - Cooperative research, 3 - Joint development, 4 - Joint institution, 5 - Scholar visit, 6 - Joint training, 7 Information exchange, 8 - Visit and investigation, 9 - Joint laboratory, 10 - Sharing of network resources, 11 - Government cooperation program. 
0 - $0.2,0.2-0.4,0.4-1$, three tiers. So that we have layered the resource conditions of the various universities international technological cooperation and exchange, then with integration international technological cooperation model selection of the various universities, we can undergo an empirical corresponding analysis.

\section{Empirical Analysis}

According to the above data acquiring methods, we apply correspondence analysis to the empirical analysis of resource conditions and pattern selection of international science and technology cooperation of university. Extraction of raw data: the number of post-graduate and doctoral students in various universities, the research funds in 2007 and the number of patents obtained in 2007 , as well as a large number of university science and technology cooperation statistics and information and the scientific judgment for the tend of cooperation model selection in various universities, according to the above approach to cope with data obtained, we got the following related data about international science and technology cooperation in universities (Table 2).

We made the multiple correspondence analysis on the data obtained, using SPSS statistical analysis software. In Figure 1, Dimension 1 and Dimension 2 respectively represent the abscissa and the vertical axis of this chart to explain the two latitudes. That is we can observe it through two directions, to draw a conclusion. Correspondence Analysis Method through the Model Summary (Table 3) shows that for these two kinds of latitude, which latitude we need to better explain the relevance of analysis. From the Inertia column in Table 3, can be seen that the interpretation of the two latitude coefficients are 0.773 and 0.413 . Thus we can see that abscissa Dimension 1 can better explain the model, so we mainly select Dimension 1 as the main direction for the interpretation of the chart.

Take the abscissa Dimension 1 as the main reference direction to analyze the points with comparatively strong relevance (Figure 1).

On the direction of Dimension 1, technology level of 0.4 or above, capital resource in the $0.4-1$, human resources of 0.7 or above, which are relatively close with the cooperation pattern of intergovernmental programs, sharing of network resources, joint laboratories, cooperative research and joint development. We can easily find out universities with plenty of science and technology cooperation resources tend to select such cooperation patterns with deep cooperation degree, intimate relationship and greater outputs.

On the direction of Dimension 1, technology level is in 0.1 - 0.4, human resources in $0.4-0.7$, and capital resource in $0.2-0.4$, which are relatively close to the cooperation pattern of cooperative research, joint development, joint training, academic conferences, visit and investigation. We can see that universities with high technology level, a good talent pool and a certain kind of research funds are fond of not only the patterns with strong academic exchanges, such as academic conference, visit and investigation, but also such cooperation patterns of more practical as cooperative research, join development.

Technology level in $0-0.1$, human resources in $0-0.4$, financial resources in $0-0.2$, universities in such level are more incline to the choice of visit and investigation, academic conference, scholar visits and exchanges, information exchange. We can see that universities with relatively limited resources conditions in science and technology cooperation would tend to choose the pattern with stronger academic exchanges cooperation.

\section{Conclusions and Discussion}

We can find out from Table 2 that there are 5 type patterns in 11 which are extensively used. They are international academic conference, cooperative research, joint development, scholar visit and exchange, joint training. If we divide China's current cooperation pattern into two categories: one is primary cooperation pattern (international academic conference, scholar visit and exchange, information exchange, visit and investigation, joint training), the other one is advanced cooperation pattern (cooperative research, joint development, joint institution, joint laboratory, sharing of network resources, government cooperation program). In fact, both the primary pattern and advanced pattern have their advantages and

Table 3. Model summary.

\begin{tabular}{ccccc}
\hline & & & \multicolumn{2}{c}{ Variance Accounted For } \\
\cline { 3 - 5 } Dimension & Cranach's Alpha & Total & Inertia & Variance \% \\
1 & 0.902 & 3.093 & 0.773 & 77.3 \\
2 & 0.527 & 1.653 & 0.413 & 41.3 \\
Total & & 4.746 & 1.187 & 59.3 \\
Mean & 0.771 & 2.373 & 0.593 & 5 \\
\hline
\end{tabular}




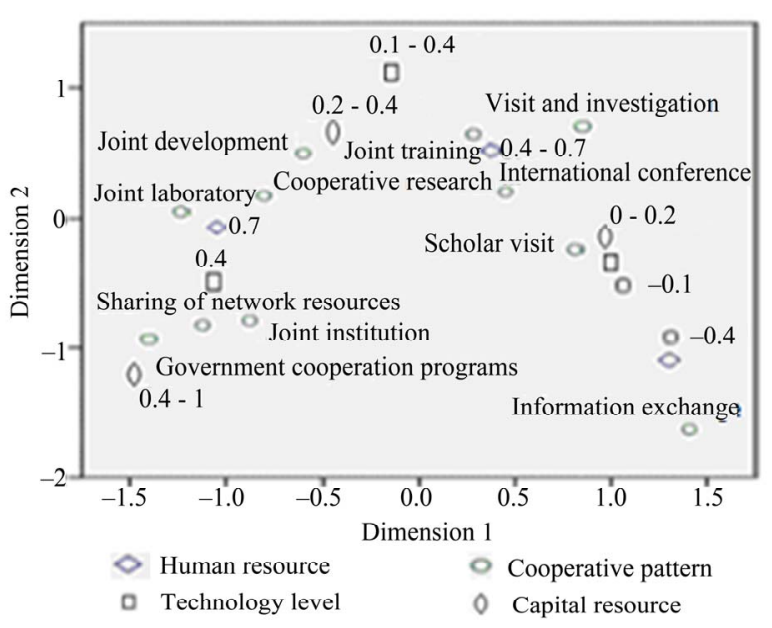

Figure 1. Variables multiple correpondence analysis map.

disadvantages, high-level cooperation patterns of cooperation require higher necessary conditions, more investment, high risks, comparatively speaking it also keep pace with further improvement in research ability, better performance. As to the primary pattern, despite of its un-significant performance, it has a relatively lower requirement on resource conditions; meanwhile the primary pattern will produce some implicit cooperation of performance (personnel training, knowledge sharing, etc.). In terms of the current status of scientific and technological resources, many universities still tend to choose the primary patterns of cooperation.

According to the research of cooperation pattern and resource conditions in universities, we sum up some questions existing in universities science and technology cooperation.

First of all, with respect to cooperation pattern, the cooperation pattern by which China's universities carry out international science and technology cooperation is still in a primitive phrase. The primary cooperation patterns, such as academic conferences and personnel information exchange are still occupying a larger proportion. The proportion of high-level science and technology cooperation patterns is still relatively small. Only a few universities with strong comprehensive strength are actively carrying out high-level cooperation pattern. Secondly, the resources for the cooperation and exchange in science and technology in China's universities are insufficient. In terms of funds for carrying out science and technology cooperation and exchange, many universities do not invest enough special funds, what' more, in many universities the funds or the matching funds are not even set. With respect to human resources, the shortage of high-quality personnel and team, causing the gap in building research team compared to the international advanced level. Besides scientific research personnel, the specialized professional management personnel and high-quality service team for universities international cooperation and exchange in science and technology are still widely needed. As for the technology level, there is still a long way to go for us to catch up with west developed countries. Also there is no specified management system for universities' carrying out science and technology cooperation. Without identified self-positioning, disable to have a good plan of the selection of cooperation pattern.

Considering the way of cooperation, universities cooperation pattern in science and technology will undergo the paradigm shift from the primary cooperation pattern to the high-level ones, and eventually showing a pattern with high science and technology cooperation-oriented pattern of cooperation. From the view of resource conditions, scientific research level and high-quality core staff, research team will take a gradually significant role co-operation in science and technology. Universities international science and technology cooperation will become increasingly tend to be specialized.

Based on the above analysis, we proposed the following policy recommendations:

Firstly, to actively promote science and technology cooperation in the form of cooperation model from primary to senior cooperation paradigms shift.

Secondly, through the study of the paper that we can fully understand the choice of cooperation pattern and resource conditions are closely related. When carrying out a specific science and technology cooperation project, universities should analyze and assess their own limited resources, be aware of their comparative advantages in resources, and then determined according to the objectives of cooperation is expected to select a suitable pattern of science and technology cooperation to achieve optimal allocation of resources.

Thirdly, resources are the first conditions of doing science and technology cooperation and exchange activities, so for a good science and technology cooperation and exchange, resources are the necessity. With the respect to input of funds, universities should set up funding for investment in science and technology cooperation, the establishment of specialized funds, but also to broaden the sources of funding to seek external funding support, and to cooperate with enterprises in aspects of science and technology R\&D and take full advantage of enterprise financial resources. In terms of team-building in scientific research, we should combine both the self-training and attracting foreign talent, and take some effective measures to retain talent for the excellent research team to provide a good research environment. And to establish a professional management services team to serve for 
universities science and technology cooperation services. International science and technology cooperation is in many aspects related to domestic and foreign policy, customs, laws, regulations, etc.

Fourth, to establish a good management system and develop effective management regulation are the guarantee for carrying out international science and technology cooperation methodically, and optimizing the allocation of resources. Universities, require the establishment of an international science and technology cooperation and exchanges for specialized management, configuration management professionals to provide quality and efficient services: fast and efficient approval of projects of cooperation and effective coordination of optimum allocation of resources, to provide the necessary support services (such as looking for good partners to effectively integrate resources, to establish channels of communication between the cooperating parties, search and collection of data and information, etc.), do a good job of public information services and establish appropriate incentive mechanism and performance evaluation mechanism.

\section{Acknowledgements}

Research works in this paper are financially supported by the Soft Science Foundation of Guangdong Province (No. 2008B070800080).

\section{REFERENCES}

[1] T. A. Finholt and G. M. Olson, "From Laboratories to Collaboratories: A New Organizational Form for Scientific Collaboration," Psychological Science, Vol. 8, No. 1, 1997, pp. 22-34. doi:10.1111/j.1467-9280.1997.tb00540.x

[2] A. Basu and R. Aggarwal, "International Collaboration in Science in India and its Impact on Institutional Performance," Scientometrics, Vol. 52, No. 3, 2001, pp. 379-394. doi:10.1023/A:1014239731175

[3] J. C. Smeby and T. Jarle, "Globalization or Europeanization? International Contact among University Staff," Higher Education, Vol. 49, No. 4, 2005, pp. 449-466. doi:10.1007/s10734-004-2826-5

[4] D. D. Beaver, "Reflections on Scientific Collaboration (and Its Study): Past, Present, and Future," Scientometrics, Vol. 52, No. 3, 2001, pp. 365-377. doi:10.1023/A:1014254214337

[5] P. Papon, "European Scientific Cooperation and Research Infrastructures: Past Tendencies and Future Prospects,"
Minerva, Vol. 8, No. 1, 2004, pp. 61-76. doi:10.1023/B:MINE.0000017700.63978.4a

[6] J. Fuqua, D. Stokols, J. Gress and K. Phillips, "Transdisciplinary Collaboration as a Basis for Enhancing the Science and Prevention of Substance Use and 'Abuse'," Substance Use \& Misuse, Vol. 39, No. 10-12, 2004, pp. 1457-1514. doi:10.1081/JA-200033200

[7] Y. Yamashita and Y. Okubo, "Patterns of Scientific Collaboration between Japan and France: Inter-sectoral Analysis Using Probabilistic Partnership Index (PPI)," Scientometrics, Vol. 68, No. 2, 2006, pp. 303-324. doi:10.1007/s11192-006-0105-1

[8] R. Ponds, "The Limits to Internationalization of Scientific Research Collaboration," Journal of Technology Transfer, Vol. 34, No. 1, 2009, pp. 76-94. doi:10.1007/s10961-008-9083-1

[9] Y. Li, L. J. Chen and H. B. Liu, "Necessity and Way of International Science and Technology Cooperation in Institutions of Higher Learning," Journal of Northeastern University (Social Science Edition), Vol. 3, No. 1, 2001, pp. 69-70.

[10] P. Feng, B. F. Sun and D. Zheng, "A Study of International Scientific and Technological Cooperation adaptation mechanism," Journal of Yanshan University, Vol. 3, 2002, pp. 57-61.

[11] J. Zhang and D. Q. Wu, "The Status, Efficiency and Tendency of International Science and Technology Cooperation between Research University and Government," Scientific Management Research, Vol. 1, No. 4, 2003, pp. 80-84.

[12] X. B. Li, B. Kong, X. C. Yang and X. J. Shi, "Study of Eastern Colleges Science and Technology Cooperation Strategy-Based on the Gaps, Complementary and Win-Win," Science \&Technology Progress and Policy, Vol. 12, 2005, pp. 164-165.

[13] P. Hu, Y. Wang and J. Ma, "Study and Thoughts on the International S\&T Cooperation of Tsinghua University," Impact of Science on Society, Vol. 3, 2006, pp. 12-16.

[14] B. J. Wu, "Research the Universities International Science and technology Cooperation on the Context of Globalization," China Agriculture Education, Vol. 6, 2007, pp. 41-42.

[15] Y. Zhang, Z. F. Chen and H. Y. He, "Management Institution Innovation in University International Sic-Tech Cooperation," Science and Technology Progress and Policy, Vol. 26, No.10, 2009, pp. 142-144. 